Available online on 15.01.2021 at http://jddtonline.info
O 2011-21, publisher and licensee JDDT, This is an Open Access article which permits
unrestricted non-commercial use(CC By-NC), provided the original work is properly cited

Open 1 Access Full Text Article

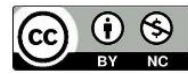

Research Article

\title{
Development and Evaluation of Nutritious Supplementary Food Product in Phenyl Hydrazine Induced Anaemia in Wistar Rats
}

\author{
Dipali Hanamghar ${ }^{*}$, Shivani Salokhe1, Sachin Tembhurane ${ }^{2}$, Swati Kolhe ${ }^{3}$ \\ ${ }^{1}$ AISSMS College of Pharmacy, Kennedy Road, Pune 411001 \\ 2 Professor at AISSMS College of Pharmacy, Kennedy Road, Pune 411001 \\ ${ }^{3}$ HOD of Pharmacology Department at AISSMS College of pharmacy, Kennedy Road, Pune 411001
}

\section{Article Info:}

\section{Article History:}

Received 18 Oct 2020;

Review Completed 20 Dec 2020

Accepted 29 Dec 2020;

Available online 15 Jan 2021

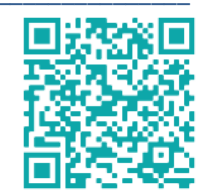

Cite this article as:

Hanamghar D, Salokhe S, Tembhurane S, Kolhe S, Development and Evaluation of Nutritious Supplementary Food Product in Phenyl

Hydrazine Induced Anaemia in Wistar Rats, Journal of Drug Delivery and Therapeutics. 2021; 11(1):68-71

DOI: http://dx.doi.org/10.22270/jddt.v11i1.4654

*Address for Correspondence:

Dipali Hanamghar, AISSMS College of Pharmacy, Kennedy Road, Pune 411001

\section{Abstract}

\begin{abstract}
Objective- Nutritional deficiency anemia mainly results from a lack of iron, but it also associated due to lack of folate/vitamin B12 and low vitamin C intake. From various studies this is found anemia in people is due to poor eating habits, such as not eating enough fruits and legumes such as beans and peas. Proper nutritional supplementation may be useful in such condition. The aim of the present work was to select a suitable iron rich food material, and prepared a suitable dosage form for management of anaemic condition and to evaluate anti-anaemic potential of nutritious supplementary food. Method- Anemia was induced by phenyl-hydrazine. Animals were treated with nutritious supplementary food throughout the study for 30 days. The haemoglobin concentration was determined after 30 days. Results- Nutritious supplementary food was found to be rich in folic acid, ascorbic acid, and iron. Following the induction of anaemia, the haemoglobin concentration decreased by $30 \%$. Administration of standard hematinic preparation and nutritious supplementary food $2 \mathrm{gm} /$ day in divided dose resulted in significant increase $(P \leq 0.05)$ in haemoglobin concentration when compared to the untreated phenyl hydrazine-induced anaemic rats. Conclusion- Nutritious supplementary food effectively raised the level of haemoglobin. Vitamin and minerals found in nutritious supplementary food are most likely active ingredients responsible for its hematinic effects.
\end{abstract}

Keywords- Anaemia, nutrition, nutritional anaemia, iron, phenyl hydrazine

\section{INTRODUCTION}

Anaemia is a condition in which the blood does not have enough healthy Red Blood Cells. Anaemia results from a lack of RBC/ dysfunctional RBC in the body. This leads to reduce oxygen flow to the body's organs ${ }^{1,2}$. Anaemia affects over $30 \%$ of the world's population, according to the World Health Organization (WHO). According to global data April 2018, India has the highest prevalence of anaemia and this even higher among Indian women with around $50 \%$ of women. It is often more common in pregnant women and children $3,4,21$.

Nutritional anaemia is an important nutritional problem affecting large population groups in most developing countries. Nutrition deficiency anaemia is common issue that can happen if the body does not absorb enough of certain nutrients. It can results from an imbalanced diet or certain health condition. Iron, folate or vitamin B12 these nutrients can cause the nutrition deficiency anemia and low vitamin $\mathrm{C}$ intake can contribute to it. Nutrition deficiencies can lead to a low red blood cell count, low of haemoglobin in these cells, or red blood cells that do not function as they should. Iron deficiency can delay the development of unborn babies 5 , 6,17 .

From various studies this is found anaemia in people is due to poor eating habits, such as not eating enough fruits and legumes such as beans and peas. So these nutrients are important for maintaining the wellbeing of human ${ }^{7,15,22}$.

Dr. Stephen Defelice coined the term "Nutraceutical" from "Nutrition" and "Pharmaceutical" in 1989. Nutraceutical is a broad term that is used to describe any product obtained from food sources. Nutraceutical product is a food supplement and it provides medical benefits to human beings. Nutraceutical provides medical benefits such as it helps in improving health, delay the aging process, prevent chronic diseases, increase life expectancy, therefore nutraceutical known as medicinally / nutritionally functional food 8,18. When food is being cooked/prepared using "scientific intelligence" with or without knowledge of how or why it is being used, the food is called "functional food". Thus functional food provides the body with the required amount of vitamins, fats, proteins, carbohydrates, etc., needed for its healthy survival. When functional food aids in the prevention and /or treatment of disease(s) and /or disorders other than anaemia, it is called a nutraceutical 8,19.

In the present innovation, composition of nutritious supplementary food contains kidney beans, soybeans, corn flakes, oats, tomato powder, beetroot powder. The composite nutraceutical preparation tested for presence of iron and folic acid. These food materials are rich source of iron, folic acid, vitamins such as vitamin C. vitamin B12, and minerals. 
Vitamin and minerals found in nutritious supplementary food are most likely active ingredients responsible for its hematinic effects ${ }^{9}$. The aim of this study was to develop and evaluate the product containing nutritious supplementary food for the management of anaemia.

\section{MATERIALS AND METHODS}

Materials- Kidney beans, oats, corn flakes, soybean, powdered sugar, baking powder, butter are collected from local market. Tomato powder and beetroot powders are collected from food masters foods LLP, kondhwa Pune411048, India.

Methods 1-

Table 1: Composition of supplementary food for $100 \mathrm{gm}$

\begin{tabular}{|l|c|}
\hline Content & Quantity (gm) \\
\hline Kidney beans & 7 \\
\hline Soybeans & 7 \\
\hline Oats & 15 \\
\hline Corn flex & 20 \\
\hline Tomato Powder & 20 \\
\hline Beet root powder & 28 \\
\hline Mannitol & 3 \\
\hline
\end{tabular}

Procedure:

Above all ingredients were collected and grind separately. All powders are sieved using sieve no.60. Each ingredient weighs and mixed well by geometric method. The final product is packed in air tight container ${ }^{10}$.

Evaluation-

1. Physical properties: Physical properties such as weight, colour, taste, density, Flowability are analysed.

Table 2: Evaluation of powder 10.

\begin{tabular}{|l|l|}
\hline Parameter & Characterization/amount \\
\hline Colour & Brownish \\
\hline Odour & Sweet \\
\hline Taste & Sour-sweet \\
\hline Bulk density & 0.4167 \\
\hline Tapped density & 0.4464 \\
\hline Flowability & 1.0712 \\
\hline
\end{tabular}

Table 3: Folic acid and iron content

\begin{tabular}{|l|l|l|l|l|l|}
\hline Sr. No & Parameter & Result & LOQ & Units & Test Method \\
\hline 1 & Iron & 7.13 & - & Mg/100g & AOAC 944.02 \\
\hline 2 & Folic Acid & $<$ LOQ & 25 & Mcg/100 g & Based on SOP030 \\
\hline
\end{tabular}

LOQ-Limit of Quantification

Method 2-

Procedure for Induction of experimental anaemia:

Anemia was induced by intraperitoneal injection of phenyl hydrazine $(60 \mathrm{mg} / \mathrm{kg}$, i.p., in divided doses daily, for 3 consecutive days. Anemia was considered to be induced when haemoglobin concentration of the blood reduced by about $30 \%{ }^{11}$.
Study group design

After induction of anemia, rats were divided into groups, except Group I comprised of healthy rats. Grouping is as follows:

Table 4: Group of animal

\begin{tabular}{|c|c|c|c|c|c|}
\hline S.N. & Category & Treatment & $\begin{array}{l}\text { No. of } \\
\text { animals } \\
\text { (Female) }\end{array}$ & $\begin{array}{l}\text { No. of } \\
\text { animals } \\
\text { (male) }\end{array}$ & Total \\
\hline 1. & Group 1 & Normal control & 3 & 3 & 6 \\
\hline 2. & Group 2 & No treatment( phenylhydrazine) & 3 & 3 & 6 \\
\hline 3. & Group 3 & Phenyl hydrazine +Std. treatment (lohasav syrup) & 3 & 3 & 6 \\
\hline 4. & group 3 & Phenyl hydrazine + Nutritious product $2.5 \mathrm{gm} /$ day in divided dose) & 3 & 3 & 6 \\
\hline 5. & Group 5 & Phenyl hydrazine + Nutritious product 5gm/day in divided dose) & 3 & 3 & 6 \\
\hline
\end{tabular}

Bio-analytical studies:

The haemoglobin concentration was determined every 7 days for 30 days.

Evaluation:

1.Hb estimation -

Procedure for $\mathrm{Hb}$ evaluation: by using drab kin's reagent

i. Pipette into 2 test tubes
Drab kin's reagent no. 1

$>$ Sample (fresh blood)

ii. Mix well. Incubation at room temperature for $5 \mathrm{~min}$.

iii. Optical density (O.D) read at 530-550 nM. The final color is stable for $30 \mathrm{~min}$.

Formula: $\quad \underline{\text { O.D.TEST } * 15.06}$ 


\section{RESULTS:}

Table 5: Result of haemoglobin concentration

\begin{tabular}{|l|l|l|}
\hline Sr.No. & Group & Mean \pm SEM \\
\hline $\mathbf{1 .}$ & Normal control & $9.332 \pm 0.3260$ \\
\hline $\mathbf{2 .}$ & No treatment( phenylhydrazine 60mg/kg) & $7.552 \pm 0.6478$ \\
\hline $\mathbf{3 .}$ & Phenyl hydrazine +Std. treatment (lohasav syrup) & $9.897 \pm 0.3356$ \\
\hline $\mathbf{4 .}$ & Phenyl hydrazine + Nutritious product 2.5 gm/day in divided dose) & $9.29 \pm 0.2197$ \\
\hline $\mathbf{5}$ & Phenyl hydrazine + Nutritious product 5 gm/day in divided dose) & $10.62 \pm 0.5098$ \\
\hline
\end{tabular}

\section{Hb estimation}

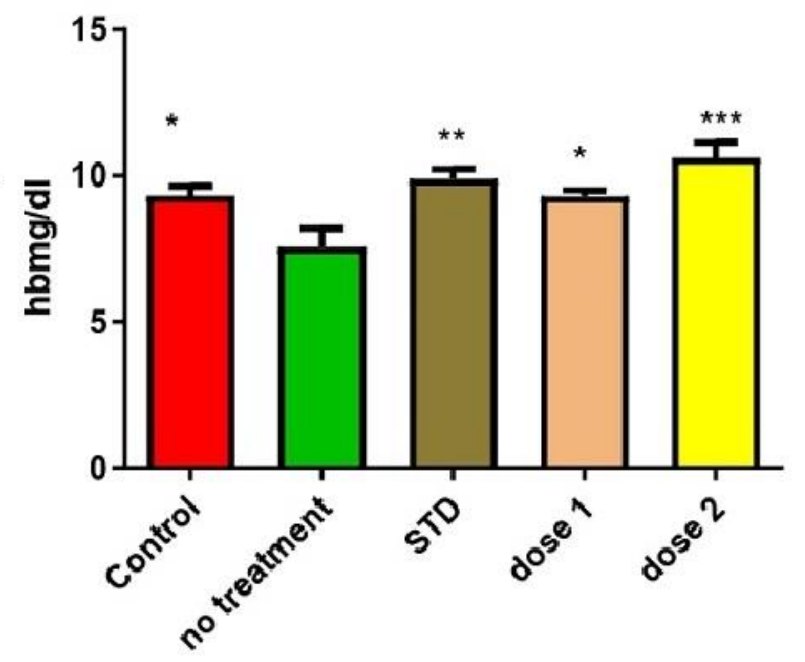

Figure 1: Effect of Nutritious Supplementary Powder on haemoglobin concentration in phenyl hydrazine induced anaemic rats.

The composite nutraceutical preparation tested for presence of iron and folic acid. The results indicates that the supplementary food/ composite nutraceutical preparation contains iron $7.13 \mathrm{mg} / 100 \mathrm{~g}$ and folic acid $25 \mathrm{Mcg} / 100 \mathrm{~g}$. Data are presented as mean \pm standard error mean and analyzed by one-way analysis of variance, followed by multiple comparison test (post-test); $\mathrm{P} \leq 0.05$ was considered as statistically significant in all analyses.

Nutritious supplementary food $2.5 / 5 \mathrm{gm} /$ day in divided dose resulted in significant increase $(P \leq 0.05)$ in haemoglobin concentration when compared to the untreated phenyl hydrazine-induced anaemic rats.

\section{Body weight-}

Table 5: Result of body weight of animal

\begin{tabular}{|l|l|l|}
\hline Sr.No. & Group & Mean \pm SEM \\
\hline 1. & Normal control & $313 \pm 0.3203$ \\
\hline 2. & No treatment( phenylhydrazine 60mg/kg) & $268.66 \pm 0.6478$ \\
\hline 3. & Phenyl hydrazine +Std. treatment (lohasav syrup) & $326 \pm 0.3356$ \\
\hline 4. & Phenyl hydrazine + Nutritious product 2.5 gm/day in divided dose) & $365 \pm 0.2197$ \\
\hline 5. & Phenyl hydrazine + Nutritious product 5 gm/day in divided dose) & $333 \pm 0.5099$ \\
\hline
\end{tabular}




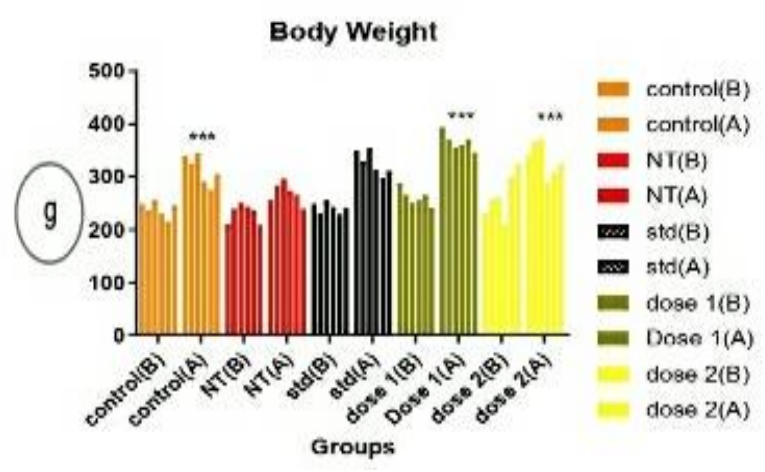

Figure 2: Effect of Nutritious Supplementary Powder on body weight of wistar rats in phenyl hydrazine induced anaemic rats.

Data are presented as mean \pm standard error mean and analyzed by one-way analysis of variance, followed by multiple comparison test (post-test); $\mathrm{P} \leq 0.05$ was considered as statistically significant in all analyses. Nutritious supplementary food 2.5/5gm/day in divided dose resulted in significant increase $(P \leq 0.05)$ in Body weight concentration when compared to the untreated phenyl hydrazine-induced anaemic rats.

\section{DISCUSSION:}

Prepared nutritious supplementary powder contains several nutritious food materials those are rich source of iron and folic acid. Therefore this nutritious supplementary powder will helpful in managing the anaemic condition. Other vitamins, minerals and proteins present in the nutritious supplementary food material will be helpful in increase the nutritious value of nutritious supplement by contributing health promoting effect.

\section{CONCLUSION:}

Nutritional deficiency anemia is due to poor intake of micronutrients such as mainly iron and folate. In the present innovation, composition of nutritious supplementary powder contains kidney beans, soybeans, corn flakes; oats, tomato powder, beetroot powder are rich source of iron and folic acid which help in managing anaemic condition in children below 5 years. Nutritious supplementary powder is rich in proteins hence it can be used in the treatment of malnourishment or nutrition deficiency. Above prepared nutritious supplementary powder tested on anaemic rats and result were found to be increase in $\mathrm{Hb}$ level of animal.

\section{Acknowledgement:}

I am equally grateful to Dr Ashwini Madgulkar, Principal and Professor of AISSMS College of Pharmacy, kenndy, Pune 411001. It gives me great pleasure to place on record my deep sense of gratitude to my project guide Ms. Swati Kolhe and Dr. Sachin Tembhurne for their encouragement and scientific temperament. My special thanks to all my colleagues for their remarkable help and support during course of my study.

\section{REFERENCES:}

1. WHO 2011, "Haemoglobin concentrations for the diagnosis of anaemia and assessment of severity, Vitamin and Mineral Nutrition Information System".(WHO/NMH/NHD/MNM/11.1) http://www.who.int/vmnis/indicators/haemoglobin. pdf.
2. Rebecca J. Stoltzfus, Luke Mullany and Robert E. Black, Iron deficiency anaemia, p. 64-204.

3. Singh S, Parihar S, "Prevalence of anemia in under five-yearold children" a hospital-based study, International Journal of Contemporary Pediatrics, 2019 Mar; 6(2):842-847, DOI: http://dx.doi.org/10.18203/2349-3291.ijcp20190740

4. International Institute for Population Sciences, Family Health Survey-2. Anemia among women and children. Mumbai: IIPS, 2000.

5. Michaelsen KF, Weaver L, Francesco Branca and Aileen Robertson, "Feeding and nutrition of infants and young children" ISBN 9289013540, ISSN 0378-2255.

6. World Health Organization 2017 Nutritional anaemia: "tools for effective prevention and control ISBN 978-92-4-151306-7.

7. Brian Thompson, Food-based approaches for combating iron deficiency, p.2-21.

8. Ekta K. Kalra (2003) Nutraceutical - Definition and Introduction. AAPS PharmSci 2003; 5(3):25 (http://www.pharmsci.org).

9. Duke, James A. 1992. Handbook of phytochemical constituents of GRAS herbs and other economic plants.

10. Gaud RS, Gupta GD, Practical Pharmaceutics, CBS Publication and distributors Pvt. Ltd. 2016, p. 164-167.

11. Jaiswal A, Ganeshpurkar A, Awasthi A, Bansal D, Dubey N, Protective Effects of Beetroot Extract against Phenyl Hydrazine Induced Anemia in Rats, PHCOG J, Sep-Oct 2014; 5:1-3.

12. Singh J, Asava \& Arishta, Lohasav, Aug 16, 2016, https://www.ayurtimes.com/lohasava-lohasavam.

13. Tawfique M, Jamal CY, "Approach to Diagnosis of Anemia in Children", Northern International Medical College Journal, DOI: http://dx.doi.org/10.3329/nimcj.v9i1.35920, Northern International Medical College Journal 2017; 9(1):248-251.

14. World Health Organization 2016, "Guideline: Daily iron supplementation in adult women and adolescent girls", ISBN 9789241510196.

15. World Health Organization 2016, "Guideline: daily iron supplementation in infants and children", ISBN 978924 1549523.

16. Deaton A, Drèze J, Food and Nutrition in India: Facts and Interpretations, february 14, 2009 vol xliv No 7.

17. Zimmermann MB, Hurrell, RF“Nutritional iron deficiency”, Lancet 2007; 370: 511-20.

18. Health supplements and nutraceuticals- Emerging high growth sector in India, world food India 2017.

19. ASA \& Associate LLP, A brief report on nutraceutical product in India, p. 2-7.

20. Broek, NVD Anaemia and micronutrient deficiencies, British Medical Bulletin 2003; 67: 149-160 DOI: 10.1093/bmb/ldg004.

21. World Health Organization 2015, The global prevalence of anaemia in 2011, ISBN 9789241564960.

22. Bhardwaj AK, Raina SK, Rapid Assessment for Coexistence of Vitamin B12 and Iron Deficiency Anemia among Adolescent Males and Females in Northern Himalayan State of India, Volume 2013, Article ID 959605, http://dx.doi.org/10.1155/2013/959605, pp.2-5. 